\title{
Current management of the mangled upper extremity
}

\author{
Marko Bumbasirevic • Milan Stevanovic • Aleksandar Lesic • \\ Henry D. E. Atkinson
}

Received: 22 July 2012 / Accepted: 25 July 2012 /Published online: 25 August 2012

(C) Springer-Verlag 2012

\begin{abstract}
Mangled describes an injury caused by cutting, tearing, or crushing, which leads to the limb becoming unrecognizable; in essence, there are two treatment options for mangled upper extremities, amputation and salvage reconstruction. With advances in our understanding of human physiology and basic science, and with the development of new fixation devices, modern microsurgical techniques and the possibility of different types of bony and soft tissue reconstruction, the clinical and functional outcomes are often good, and certainly preferable to those of contemporary prosthetics. Early or even immediate (emergency) complete upper extremity reconstruction appears to give better results than delayed or late reconstruction and should be the treatment of choice where possible. Before any reconstruction is attempted, injuries to other organs must be excluded. Each step in the assessment and treatment of a mangled extremity is of utmost importance. These include radical tissue debridement, prophylactic antibiotics, copious irrigation with a lavage system, stable bone fixation, revascularization, nerve repair, and soft tissue coverage. Well-planned and early rehabilitation leads to a better functional outcome.
\end{abstract}

\footnotetext{
M. Bumbasirevic $(\bowtie) \cdot$ A. Lesic

School of Medicine, Clinic of Orthopaedic Surgery and Traumatology, Clinical Centre, University of Belgrade, Visegradska 26,

11000 Belgrade, Serbia

e-mail: marko.bumbasirevic@gmail.com

M. Stevanovic

Deparetment of Orthopaedics, University of Southern California Keck School of Medicine,

Los Angeles, CA, USA

H. D. E. Atkinson

Departemnt of Trauma and Orthopaedics, North Midlesex University Hospital and London, Sports Orthopaedics, Sterling Way N18 1QX, UK
}

Despite the use of scoring systems to help guide decisions and predict outcomes, the decision to reconstruct or to amputate still ultimately lies with the surgical judgment and experience of the treating surgeon.

\section{Introduction}

Mangled is the descriptive term for an injury caused by cutting, tearing, or crushing, resulting in a limb becoming unrecognizable. A mangled extremity usually results from major trauma and often combines significant injuries to three or four of the tissue types (bone, skin, arteries, nerves) [1]. A search of the literature, however, has found that the term "mangled" has also been used to describe severe mutilating injuries, open fractures, blast injuries, and complete or incomplete amputations (Fig. 1). To elaborate, a search of Pubmed under the keyword "mangled" found 137 articles: 41 containing "mangled" in the title, five pertaining to the upper limb and nine to the lower limb); and 82 articles relating to blast, severe and vascular injuries, total or partial amputations, and renal failure secondary to trauma.

Most mangled injuries occur following high energy trauma and can be associated with other life threatening injuries, thus one should initially abide by the golden "life before limb" mantra before contemplating any reconstructive surgery [2-4].

Despite advances in microsurgical techniques, the treatment of severely injured limbs remains a great challenge to the reconstructive surgeon. Limb salvage can be difficult in its own right, and the restoration of good limb function can be an even greater challenge [5-10]. However, limb salvage should be attempted where possible, and at the very least the salvage of as 
Fig. 1 A case of complete upper extremity amputation. After the replantation transpositional latissimus pedicle functional flap was done in order to obtain elbow flexion. Even after the proximal level replantation a good nerve recovery with reasonable function is possible
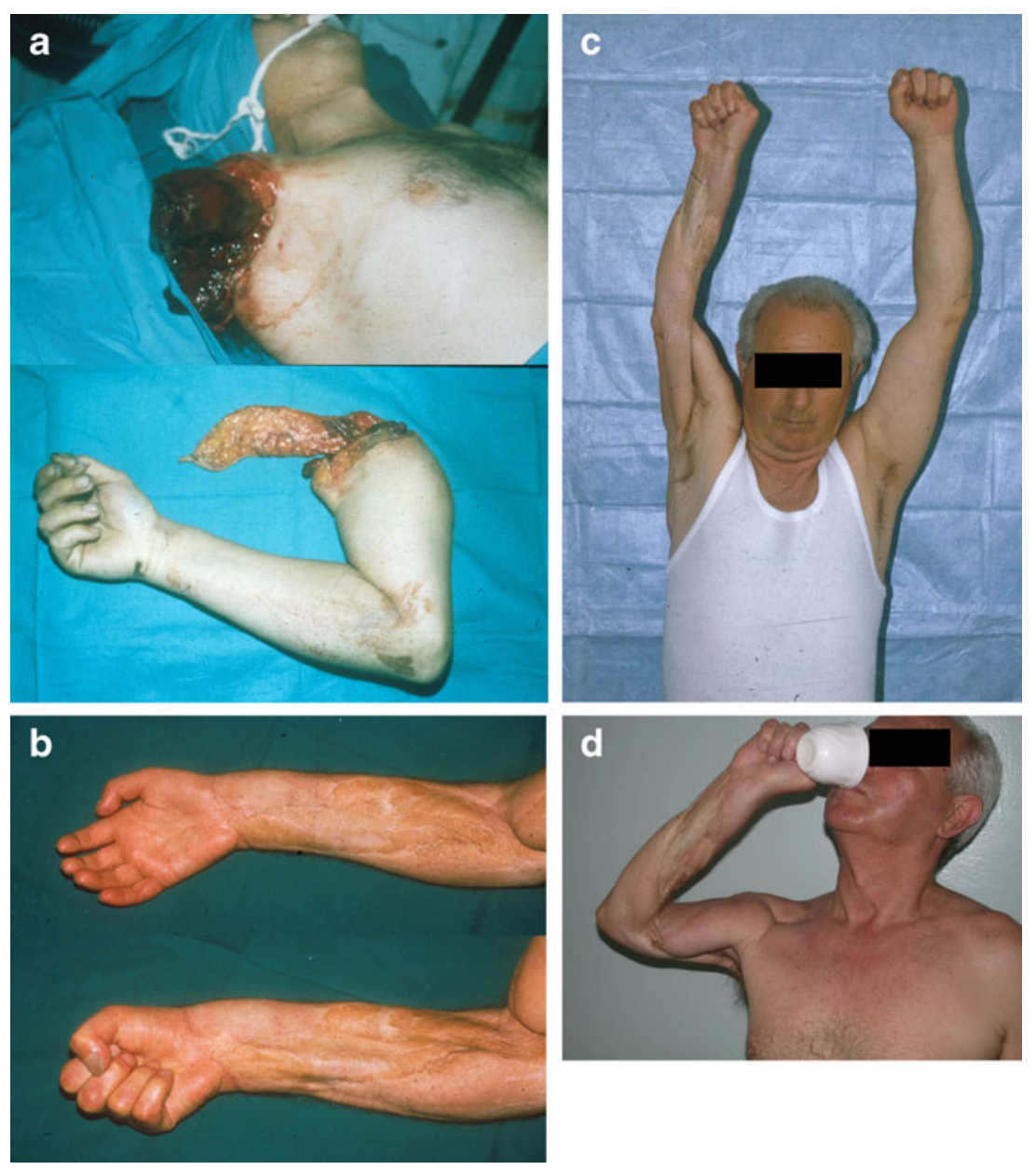

much viable tissue as possible [11]; in preference to an amputation, which is associated with persisting pain in around 30-79 \% of patients [4]. Though cheaper than staged, sometimes unpredictable, surgical reconstructions, modern upper limb prosthetics fail to give the same satisfactory functional and aesthetic results compared with those used in the lower limb (and direct comparisons show that upper limb reconstructions are superior to prosthetics [12-14]. Prosthetic devices cannot substitute even a moderately functional hand and its sensitivity [15]; and a "bad hand" is still functionally better than a "good upper limb prosthesis"; $30 \%$ of patients even stop using their prostheses altogether [4].

Several scoring systems have been devised in order to assist in the surgical decision making process in lower limb salvage, though there are only few for the upper limb [16-21]. These scoring systems are difficult to use when deciding on the definitive treatment of a mangled upper extremity, and do not predict functional outcomes [23]. Hence, the decision to reconstruct or to amputate still commonly lies with the surgical judgment and experience of the treating surgeon [23-25].
General considerations

These complex injuries are accompanied by significant tissue damage with tissue ischaemia, vascular impairment and thrombosis, and are associated with high levels of infection $[5,24]$. Patient factors are also important, and functional outcomes depend on the patient age, general health status (the coexistence of peripheral vascular disease, diabetes mellitus, atherosclerosis), patient psychology and expectations, and the use of steroids and other immunosuppressants $[8,14,24]$. One should base the treatment plan on the expected levels of function one might obtain after surgery and rehabilitation.

The initial assessment

A thorough history is obtained, providing information regarding the circumstances, mechanism, sites and timing of the injury (the how, when and where). Most upper limb mangled injuries occur following high energy trauma and can be accompanied by life threatening injuries [18, 24]; these are dealt with first. 
The mechanism of the injury commonly dictates the patterns and anatomical levels of the trauma. Distal, sharp (clean) injuries have a better prognosis than, proximal traction, torsional, and crush injuries [10, 14]. Though this might appear obvious, some studies have not found any statistically significant correlation between these characteristics and patient outcomes [26]. Knowledge of any associated machinery can also indicate patterns of damage (e.g. avulsion, crush, degloving, incising injuries). Chemical and thermal injuries can result in more extensive tissue damage [24]. Knowledge of where the injury took place is also helpful as some locations are associated with higher levels of contamination (e.g. farms) and industrial locations can involve chemical damage, burns, and high pressure injection injures [27-29].

Tissue ischaemia time is also an extremely important factor. Ischaemia leads to various metabolic changes and the release of oxygen free radicals, and patients can have serious systemic reperfusion injuries following surgery [8]. Infection risk greatly increased after six-12 hours of cold ischaemic time; muscles are intolerant of a warm ischaemic time of more than four to six hours (12 h of cold ischaemia), though the hand and digits can "survive" up to the 24 hours of cold ischaemia [13, 30]. Wei even reported a successful digital replantation after a cold ischaemia time of 94 hours [31]. There is also a greater risk of compartment syndrome early in the post injury period, and one must have a low threshold for performing fasciotomies [32].

A careful clinical examination of the injured extremity is performed. Particular attention is given to the limb vascularity, skeletal stability, motor and sensory deficit, and soft tissue and skin loss $[14,33,34]$. The vascular status is assessed through peripheral pulses, skin color, temperature and capillary refill [24]. Pulse oximetry is readily available in emergency rooms and can be helpful; Doppler ultrasound and arteriography is of the limited value in this context [32]. Skeletal injuries are assessed clinically and with plain radiography (tangential and traction radiographs of the whole extremity). Nerve injures are evaluated through assessing residual motor function and any sensory loss; nerve injuries are common in sharp, incising injuries, and can be easy overlooked. The full extent and degree of tissue destruction (the zone of injury) is only ever definitively verified after the initial surgical debridement and complete wound exploration, where all these tissues are directly assessed $[35,36]$.

\section{Treatment}

The initial management of the mangled limb should follow the Advanced Trauma Life-Support (ATLS) guidelines which aim to resuscitate and stabilize the patient and address any immediately life threatening injuries [14, 37].
Following the primary survey one can then hone in on the mangled limb. Any bleeding from the injured limb must be controlled with pressure and a compressive dressing, or, failing this, a tourniquet until the bleeding vessels can be identified and repaired, or the limb revascularized. When a mangled extremity is ischaemic for long periods then one should use carotid vascular shunts to the brachial, radial or ulnar arteries (after the removal of distal segment thrombotic masses) [38]. Where there has been an amputation, the amputated part must be cooled (to prolong its potential ischaemic time; this can be up to six hours for large muscle masses). Cooling is achieved by wrapping the part in salinesoaked gauze and then kept in a plastic bag with iced water at $4{ }^{\circ} \mathrm{C}$. Any skeletal deformity, malalignment of dislocation should be reduced; this too can improve the peripheral circulation. After bacterial culture swabs are taken from the damaged tissue, one can administer antibiotics and tetanus prophylaxis. A combination of first generation cephalosporins for not less than five days and aminoglycosides are used; high-dose penicillin and metronidazole should be used where there is suspicion of an anaerobic bacterial contaminant [39].

Operative treatment begins with copious irrigation and preferably with a jet or pulsed lavage; this helps to remove foreign material and frees the devitalized from the healthy tissues. This is followed by radical wound debridement removing all obviously dead/devitalized tissue as one might approach a tumor excision [11]. It is seldom possible to debride all necrotic tissue at the initial surgery and often second and third look debridement surgery is necessary at 24 and 36 hours [40-42]; one should bear in mind that no amount of irrigation can replace debridement. Debridement should be done under tourniquet control so as to have better visualization and avoid iatrogenic injury [14, 35]. Nerves should be preserved wherever possible, while other devascularized tissues including bone and muscle (and even injured blood vessels) should be excised. At this stage one can also decompress the fascial compartments, particularly in the forearm and hand, where appropriate $[32,35]$.

The next step is to stabilize the fractures, as skeletal stability forms a solid base for all the other tissue reconstructions. External fixation is the method of choice for most severe open fractures, though other fixations systems including rigid internal fixation (for long bone fractures of the humerus, radius and ulna) (Fig. 2) [5, 24] or supplementation with K-wire fixation (particularly with phalangeal, metacarpal and carpal bone injuries, can also be appropriate, because metal, per se, is not the cause of infection. Plating of the long bones can also facilitate any necessary bone shortening procedures, and in cases where the bones are shortened to allow for direct primary end-to-end anastomoses and grafting of injured vessels and nerves. 
Fig. 2 A case of the severe distal forearm injury. After the revascularization, tendon reconstruction a free omental flap was done. A very good functional result was obtained
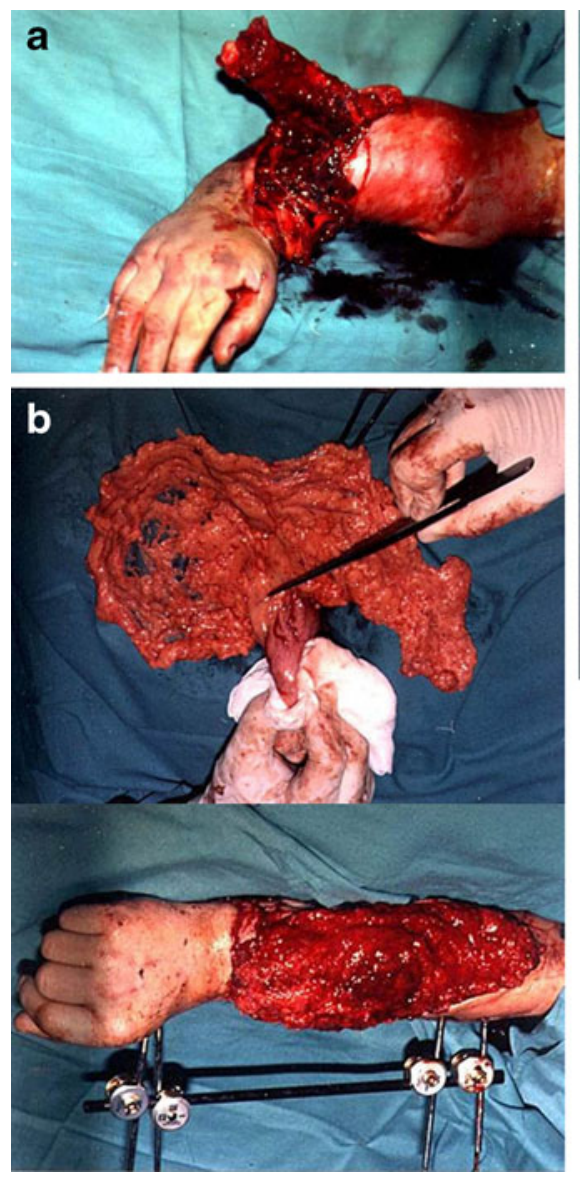

The humerus can be shortened up to $5 \mathrm{~cm}$, and the forearm up to $4 \mathrm{~cm}[29,43]$. Axelrod's work strongly supports bone shortening, with good to excellent published results using the Chen Criteria [26]; however, excessive bony shortening leads to muscle deficiency/mechanical insufficiency (particularly in the forearm) and is not possible with some injury patterns (such as Monteggia and Galeazzi fractures) [5]. Larger bone defects, greater than $4 \mathrm{~cm}$, necessitate primary bone grafting from the iliac crest. Defects larger still, longer than $6 \mathrm{~cm}$, require vascularized fibula grafts.

Intra-articular fractures must be if possible anatomically reduced and stabilized, the goal being to enable early joint motion, while also allowing the capsule and ligaments time to heal. The joints must be covered with a well vascularized soft-tissue envelope [44]. In cases with severe comminution, one may use a bridging external fixator (across the wrist, MCP and IP joints); mini external fixators are advisable for mangled injuries involving the first web space to prevent the development additional contractures [30]. Alternatively, primary allograft or joint prostheses can be a treatment option for the larger upper joints (elbow and shoulder). Stability is more important (than mobility) in the wrist, and primary fusion may be the best option. [45].
Vascular reconstruction is performed after the fractures have been stabilized. In multiple level injuries one generally starts by repairing the more proximal vascular injury, and then working distally. Temporary shunts with heparinized plastic tubes are utilized (before definitive revascularization) if the ischaemia has been prolonged (greater than four hours) [24]. Using magnification, injured vessels are trimmed back to healthy viable tissue and undergo primary repair, without tension. Vein grafts can be used where there is doubt about vessel viability or tissue tension, and there is no place for the use of artificial grafts. Reversed saphenous vein grafts are most commonly used. Smaller diameter vein grafts can be obtained from the dorsum of the hand, superficial forearm veins and from the "spare parts" in the mutilated extremity [46]. Longer defects can be spanned with a peroneal artery graft. Veins should also be reconstructed wherever there is suspicion of inadequate venous drainage.

Tendon repairs and musculotendinous reconstructions are addressed next. Early primary tendon restoration is preferable, and early protected motion/dynamic immobilization is vital to preserve tendon function and prevent scar tissue adhesions; this is particularly important with flexor tendons. The flexor tendons should be repaired directly where possible; however, where there is a tendon defect or tissue 
destruction, one should use a graft such as the palmaris longus. Tendon transfers and transpositions can be done at a later stage [6], and side-to-side tenodeses can also yield good results. However, passive or active silicone tendon rods should be used to reduce the problems associated with scar tissue when one needs to perform delayed or staged reconstructions [25]. Where there is very severe muscle destruction, one may need to perform free microsurgical functional muscle transfers; gracilis and latissumus dorsi are the most commonly used grafts [9].

Nerve reconstruction is probably the most unpredictable surgical stage. A meticulous surgical repair is of the utmost importance; however, the functional results depend on a variety of other non-surgical factors including the age of the patient, the level of the injury (the more proximal the more unpredictable), and the degree of tissue damage (it can be extremely difficult to macroscopically distinguish between axonotmesis and neurotmesis, and even the degree of nerve gap). Nerves should be repaired acutely to avoid the technical problems of scar tissue formation encountered with secondary reconstructions. Care should be taken to orient the nerve fascicles and surgeons should use a microscope or surgical loupes. One must avoid tension at the repair site, at all costs. Small nerve gaps can be resolved by mobilizing the nerve ends, through proximal nerve transpositions, or by using bridging veins, nerve conduits, silicone and absorbable tubes [47-49]. Although the epineural microsurgical suture is mostly performed, there is also the proposition for microsurgical interfascicular nerve grafting when there are larger gaps [50]. Primary nerve transfers can be performed in multiple nerve injuries, for example an anterior interosseous nerve transferred to the motor ulnar nerve, or the sensory branch of the radial nerve transferred to the digital nerves for the first two digits (thumb and index finger). Alternatives methods such as an "end-to-side" anastomosis (where the distal stump of injured nerve is sutured to an adjacent intact major nerve) can be used as a last resort if the laceration is greater than $15 \mathrm{~cm}$.

Despite the long-held belief that wounds associated with severe open fractures should be left open, the concept of early coverage of soft-tissue defects is becoming increasing widely accepted [11, 40, 44, 51, 52]. It is very important to get good biological wound coverage with well-vascularized tissue (preferably muscle flaps) as soon as possible (preferably during the first 72 hours, even if there is a positive wound culture [51]; and particularly in the mangled upper extremity [42]. These muscle flaps cover and protect the bones, joints, tendons, vessels, and nerves and bring vascularity, oxygenation, biological agents, immune elements and antibiotics to the zone of injury; all of which help to combat infection, reduce morbidity and reduce the times to healing. Wounds must never be closed tightly, due to the risks of ischaemia and wound dehiscence, and temporary and loose wound closures are sometimes necessary in burns, highpressure injection and crush injuries [41].

The choice of graft is determined by the size and location of the defect and follows the "reconstructive ladder" principles [53].

The mangled hand deserves special attention, and, as Sterling Bunnell famously said, "when you have nothing, a little is a lot" $[10,54,55]$. Thus, even in the extremely injured limb there is functional benefit if prehension and sensation is restored. The functional outcome depends on the preservation and restoration of mobile and functioning musculo-tendinous units and any tissue coverage must be stable and not restrict the range of motion. It must also be sensate and cosmetically acceptable; therefore, fascial or thin muscle flaps are preferable to bulky musculocutaneous flaps on the palmar/volar aspect of the hand. One should also consider the basic rules regarding the bones and joints. The length of the bones is not so important, but motion must be preserved in certain joints, DIP joints and the thumb IP joint can be fused, but not the PIP joints. The MCP needs $35^{\circ}$ of motion, but it is also better to have a stable/fused joint than a painful and unstable joint [30].

\section{Postoperative rehabilitation}

Following surgery one must protect the reconstructed limb while also allowing early motion to promote tendon gliding and to prevent joint contractures and tissue oedema. One should adopt a patient-specific approach to meet each individual's needs, paying attention to the type and extension of the injuries, and the stability of the bony and other reconstructed tissues [56]. Rehabilitation is divided into different stages; early-protective, immediate-mobilization, and latestrengthening, and consists of static and dynamic bracing, physical therapy and occupational therapy. Patients also benefit from psychological support and social assistance as post-traumatic stress disorder (PTSD) and depression is common following these catastrophic injuries [55].

\section{Complications and secondary surgery}

The most common and serious complications include deep infection, osteomyelitis, loss of tissue flaps, reflex sympathetic dystrophy, and vein graft thrombosis [14, 19, 38]. Some authors have reported having to perform secondary reconstructions for failed primary procedures in $45 \%$ of hand and digital replant patients [57]. Secondary procedures can include simple adhesiolysis, tenolysis, capsulotomies, Z-lengthening of contracted scars, local flaps, nerve grafting, and tendon transfers $[58,59]$. The absence of the thumb can be overcome by pollicization of the second digit or through the Morrison procedure [60]. The thumb can also be elongated with an external fixator and distraction [37]. 
Hand and composite tissue transplants hold some promise and are likely to yield better future results [4]

Despite the severity of tissue damage presented by the mangled upper limb, we have seen that reasonable and good functional outcomes can be obtained but the function result can never match the function of uninjured upper limb.

Maybe in the future the functional results can be improved with the advanced technique of cadaveric tissue transplant, better immunosuppression drugs, or by use of the new more sophisticated prosthesis such as bionic hand [61-67].

\section{References}

1. Gregory RT, Gould RJ, Peclet M, Wagner JS, Gilbert DA, Wheeler JR, Snyder SO, Gayle RG, Schwab CW (1985) The mangled extremity syndrome (M.E.S.): a severity grading system for multisystem injury of the extremity. J Trauma 25(12):1147-1150

2. Covey DC (2002) Blast and fragment injuries of the musculoskeletal system. J Bone Joint Surg Am 84A(7):1221-34

3. Okike K, Bhattacharyya T (2006) Trends in the management of the open fractures, a critical anlysis. J Bone Joint Surg Am 88 (12):2739-48, Review

4. Tintle SM, Baechler MF, Nanos GP, Forsberg JA, Potter BK (2010) Traumatic and trauma-related amputations: part II:upper extremity and future directions. J Bone Joint Surg Am 92 (18):2934-45

5. Heller L, Levin S (2006) In: Bucholz RW, Heckman JD, CourtBrown C (eds) Bone and soft tissue reconstruction in "Rockwood and Green's fractures in adults", 6th edn. Lippincott Co, Philadelphia, pp 497-547

6. Brown HC, Williams HB, Woolhouse FM (1968) Principles of salvage in mutilating hand injuries. J Trauma 8:319-332

7. Faibisoff B, Daniel RK (1981) Management of severe forearm injuries. Surg Clin North Am 61(2):287-301

8. Bueno RA Jr, Neumeister MW (2003) Outcomes after mutilating hand injuries: review of the literature and recommendations for assessment. Hand Clin 19(1):193-204

9. Stevanovic M, Gutow AP, Sharpe F (1999) The management of bone defects of the forearm after trauma. Hand Clin 15(2):299-318

10. Brown JB, Cannon B, Graham B, Davis WB (1949) Restoration of major defects of the arm by combination of plastic, orthopedic and neurologic surgical procedures. Plast Reconstr Surg 4(4):337-340

11. Bumbaširević $M$, Lešić A, Mitković M, Bumbaširević V (2006) Treatment of blast injuries of the extremity. J Am Acad Orthop Surg 14(10):S77-81

12. Bosse MJ, MacKenzie EJ, Kellam JF, Burgess AR, Webb LX, Swiontkowski MF, Sanders RW, Jones AL, McAndrew MP, Patterson BM, McCarthy ML, Travison TG, Castillo RC (2002) An analysis of outcomes of reconstruction or amputation after leg-threatening injuries. N Engl J Med 347(24):1924-1931

13. Graham B, Adkins P, Tsai TM, Firrel J, Breidenbach WC (1998) Major replantation versus revision amputation and prosthetic fitting in the upper extremity: a late functional outcomes study. J Hand Surg Am 23(5):783-791

14. Neumeister MW, Brown RE (2003) Mutilating hand injuries: principles and management. Hand Clin 19:1-15

15. Peacock K, Tsai TM (1987) Comparison of functional results of replanation versus prosthesis in a patient with bilateral arm amputation. Clin Orthop Relat Res 214:153-159

16. Dirschl DR, Dahners LE (1996) The mangled extremity: when should it be amputated? J Am Acad Orthop Surg 4(4):182-190
17. Howe HR Jr, Poole GV Jr, Hansen KJ, Clark T, Plonk GW, Koman LA, Pennell TC (1987) Salvage of lower extremities following combined orthopaedic and vascular trauma. A predictive salvage index. Am Surg 53(4):205-208

18. Johansen K, Daines M, Howey T, Helfet D, Hansen ST Jr (1990) Objective criteria accurately predict amputation following lower extremity trauma. J Trauma 30(5):568-573

19. Russell WL, Sailors DM, Whittle TB, Fisher DF Jr, Burns RP (1991) Limb salvage versus traumatic amputation. A decision based on a seven-part predictive index. Ann Surg 213(5):473-480

20. Mcnamara MG, Heckman JD, Corley FG (1994) Severe open fractures of the lower extremity: a retrospective evaluation of the Mangled Extremity Severity Score (MESS). J Orthop Trauma 8 (2):81-87

21. Lange RH, Bach AW, Hansen ST Jr, Johansen KH (1985) Open tibial fractures with associated vascular injury: prognosis for limb salvage. J Trauma 25:203-208

22. Slauterbeck JR, Britton C, Moneim MS, Clevenger FW (1994) Mangled extremity severity score: an accurate guide to treatment of the severely injured upper extremity. J Orthop Trauma 8 (4):282-285

23. Durham RM, Mistry BM, Mazuski JE, Shapiro M, Jacobs D (1996) Outcome and utility of scoring systems in the management of the mangled extremity. Am J Surg 172(5):569-573

24. Gupta A, Shatford RA, Wolf TW, Tsai TM, Scheker LR, Levin LS (2000) Treatment of the severly injured upper extremity. Instr Course Lect 49:377-396

25. Korompilias AV, Beris AE, Lykissas MG, Vekris MD, Kontogeorgakos VA, Soucacos PN (2009) The mangled extremity and attempt for limb salvage. J Orthop Surg Res 4:4, 13

26. Axelrod TS, Büchler U (1991) Severe complex injuries to the upper extremity: revascularization and replantation. J Hand Surg Am 16(4):574-584

27. Gorsche TS, Wood MB (1988) Mutilating corn-picker injuries of the hand. J Hand Surg Am 13(3):423-427

28. Campbell DC 2nd, Bryan RS, Cooney WP 3rd, Ilstrup D (1979) Mechanical cornpicker hand injuries. J Trauma 19(9):678-681

29. Ring D, Jupiter JB (1999) Mangling upper limb injuries in industry. Injury 30(Suppl 2):B5-13

30. Vedder N, Hanel D (2011) In: Wolfe SW, Hotchkiss RN, Pederson WC, Kozin SH (eds) The mangled upper extremity in "Green's Operative Hand surgery”, 6th edn. Elsvier, Churchill Livingstone, Philadelphia, pp 1603-1644

31. Wei FC, Chang YL, Chen HC, Chuang CC (1988) Three successful digital replantation in a patient after 84,86 and $94 \mathrm{~h}$ of cold ischemia time. Plast Reconstr Surg 82(2):346-350

32. McGee DL, Dalsey WC (1992) The mangled extremity. Compartment syndrome and amputations. Emerg Med Clin North Am 10 (4):783-800

33. Charalampos Z, Shepherd L, Sharpe F, Stevanovic M (2003) Management of the mangled upper extremity. In: Malizos KN (ed) Reconstructive microsurgery. Landes Bioscience, Georgetown, TX, pp 57-73

34. Seal A, Stevanovic M (2011) Free functional muscle transfer for the upper extremity. Clin Plast Surg 38(4):561-575

35. Burkhalter W (1986) Mutilating injuries of the hand. Hand Clin 2 (1):45-68

36. Brown PW (1979) The fate of exposed bone. Am J Surg 137 (4):464- 469

37. Bernstein ML, Chung KC (2007) Early management of the mangled upper extremity. Injury 38(Suppl 5):S3-7

38. Granchi T, Schmittling Z, Vaszquez J, Schreiber M, Wall M (2000) Prolonged use of intraluminal arterial shunts without systemic anticoagulation. Am J Surg 180(6):493-496

39. Hoffman RD, Adams BD (2003) Antimicrobial management of mutilating hand injuries. Hand Clin 19(1):33-39 
40. Francel TJ, Vander Kolk CA, Hoopes JE, Manson PN, Yaremchuk MJ (1992) Microvascular soft-tissue transplantation for reconstruction of acute open tibial fractures: timing of coverage and longterm functional results. Plast Reconstr Surg 89(3):478-489

41. Giessler GA, Erdmann D, Germann G (2003) Soft tissue coverage in devastating hand injuries. Hand Clin 19(1):63-71

42. Ricci MW, McAndrew C, Merriman D, Gardner MJ (2011) What's new in orthopaedic trauma. J Bone Joint Surg Am 93(18): 1746-1756

43. Meyer VE (1985) Hand amputation proximal but close to the wrist joint: prime candidates for reattachement (long term functional results). J Hand Surg Am 10(6 Pt 2):989-991

44. Godina M (1986) Early microvascular reconstruction of complex trauma of extremities. Plast Reconstrct Surg 78:285-292

45. Bilic R, Kolundzic R, Bicancic G, Korzinek K (2005) Elbow arthrodesis after war Iinjuries. Mil Med 170:164-166

46. Brown Re WTY (2003) Use of "spare parts" in mutilated upper extremity injuries. Hand Clin 19(1):73-87

47. Weber RA, Breidenbach WC, Brown RE, Jabaley ME, Mass DP (2000) A randomized prospective study of polyglycolic acid conduits for digital nerve reconstruction in humans. Plast Reconstr Surg 106(5):1036-1045

48. Stanec S, Stanec Z (1998) Reconstruction of upper -extremity peripheral- nerve injuries with ePTFE conduits. J Reconstr Microsurg 14(4):227-232

49. Mackinnon SE, Dellon AL (1990) Clinical nerve reconstruction with a bioabsorbable polyglycolic acid tube. Plast Reconstr Surg 85(3):419-424

50. Stancic MF, Eskinja N, Bellinzona M, Micovic V, Stosic A, Tomljanovic Z (1996) The role of interfascular nerve grafting after gunshot wounds. A report of 44 cases. Int Orthop 20(2):87-91

51. Lenarz CJ, Watson JT, Moed BR, Israel H, Mullen JD, MacDonald JB (2010) Timing of wound closure in open fractures based on cultures obtained after debridement. J Bone Joint Surg Am 92(10):1921-1926

52. Lister G, Scheker L (1988) Emergency free flaps to the upper extremity. J Hand Surg Am 13(1):22-28

53. Levin L (1993) The reconstructive ladder. An orthoplastic approach. Orthop Clin North Am 24:393-409
54. Meyer TM (2003) Psychological aspects of mutilating hand injuries. Hand Clin 19(1):41-49

55. Grunert BK, Smith CJ, Devine CA, Fehring BA, Matloub HS, Sanger JR, Yousif NJ (1988) Early psychological aspects of severe hand injury. J Hand Surg Br 13(2):177-180

56. Chan SW, LaStayo P (2003) Hand therapy management following mutilating hand injuries. Hand Clin 19(1):133-148

57. Lutz BS, Klauke T, Dietrich FE (1997) Late results after microvascular reconstruction of severe crush and avulsion injuries of the upper extremity. J Reconstr Microsurg 13(6):423-429

58. Russel RC, Bueno RA Jr, Wu TY (2003) Secondary procedures following mutilating hand injuries. Hand Clin 19(1):149-163

59. Jupiter JB, Pess GM, Bour CJ (1989) Results of flexor tendon tenolysis after replantation in the hand. J Hand Surg Am 14 (1):35-44

60. Morrison WA, Macleod AM, O'Brien BM (1982) Digital reconstruction in the mutilated hand. Ann Plast Surg 9(5):392-399

61. Shores JT, Imbriglia JE, Lee WP (2011) The current state of hand transplantation. J Hand Surg Am 36:1862-1867

62. Siemionow M, Ozer K (2002) Advances in composite tissue allograft transplantation as related to the hand and upper extremity extremity. J Hand Surg Am 27:565-580

63. Foroohar A, Elliot RM, Kim TW, Breidenbach W, Shaked A, Levin LS (2011) The history and evolution of hand transplant. Hand Clin 27:405-409

64. Clement RG, Bugler KE, Oliver CW (2011) bionic prosthetic hands: A review of present technology and future aspirations. Surgeon 9:336-340

65. Di Pino G, Guglielmelli E, Rossini PM (2009) Neuroplasticity in amputees: main implications on biderctional interfacing of cybernetic hand prostheses. Prog Neurobiol 88:114-126

66. Risso RR (1999) Strategies for providing upper extremity amputees with tactile and hand position feedback-moving closer to the bionic arm. Technol Healt Care 7:401-409

67. Moise A, Constatinescu I, Sarbenascu B, Gingu CV, Zamfirescu DG, Lascar I (2011) Hand Transplant - a challenge in imunological management of patients. J Med Life 4:287-290 